\title{
Magnesium pemoline: Effects on the learning and retention of a conditioned avoidance response by rats
}

\author{
JAMES E. MCCARROLL ${ }^{\wedge}$ AND SUSAN F. KORBEL, \\ DEPARTMENT OF PSYCHOLOGY, UNIVERSITY OF \\ ARKANSAS, Fayetteville, Arkansas
}

Thirty-two albino male rat Ss were randomly assigned to four groups which were trained to perform a conditioned avoidance response to a criterion of acquisition. They were tested for retention at $24 \mathrm{~h}$ and $72 \mathrm{~h}$. In acquisition, three of the four groups were given $\mathrm{MgPe}$ while a control group was given a placebo. After $24 \mathrm{~h}$, two groups were drug-treated and two were placebo-treated. After $72 \mathrm{~h}$, one group was drug-treated and three were placebotreated. It was found that $\mathrm{MgPe}$ did facilitate learning, but not retention. It was concluded that differences in retention were probably related to the acquisition process and not to $\mathrm{MgPe}$.

The purpose of this experiment was to investigate the effects of magnesium pemoline ( $\mathrm{MgPe}$ ) on the learning and extinction of a conditioned avoidance response by rats. It was hypothesized that in acquisition Ss treated with MgPe would show a shorter latency of response, a higher proportion of avoidances and fewer trials to a criterion of learning. The hypothesis tested in extinction was that drug-treated Ss would require more trials to criterion than controls.

Subjects. The Ss were 32 naive male albino rats ( 240 to $420 \mathrm{~g}$ ) obtained from the University of Arkansas Animal Science Center (local strain).

Apparatus. The apparatus used was a one-way avoidance box. The Ss' task was to jump a hurdle 3 in. high to pass from the shock side to the safe side. The apparatus and the reasons for using it have been described elsewhere (McCarroll \& Korbel, 1967). The unconditioned stimulus (UCS) was a 0.3 $\mathrm{mA}$ shock delivered through brass rods by a Grason-Stadler (E6070B) shock generator and scrambling mechanism. The conditioned stimulus (CS) was presented by a buzzer of low intensity which was situated below the floor of the shock compartment. The interstimulus interval was $5 \mathrm{sec}$. Latency and trials to criterion were used as the measures of Ss' acquisition behavior. In extinction, trials to criterion constituted the only measure since latency scores could not be obtained for all Ss due to the fact that some extinguished by the first trial. The $\mathrm{MgPe}$ was prepared in suspension form in $0.5 \%$ carboxymethycellulose which was filtered through a Seitz bacteriological filter before the MgPe was added. ${ }^{2}$ Each $S$ was injected intraperitoneally with $3.1 \mathrm{mg}$ of $\mathrm{MgPe}$ which was approximately $10 \mathrm{mg} / \mathrm{kg}$ body weight of each rat. All Ss were injected $30 \mathrm{~min}$ before they were to be tested. All Ss were run by the first author who did not know at the time whether a $S$ was drug or placebo-treated. ${ }^{3}$

Procedure. All Ss were tested at acquisition and at two extinction sessions, after $24 \mathrm{~h}$ and $72 \mathrm{~h}$. The $32 \mathrm{Ss}$ were assigned randomly to four groups. Group E1 received MgPe at acquisition and at both extinction sessions; E2 received $\mathrm{MgPe}$ at acquisition and the first extinction session, but the placebo (carboxymethylcellulose) at the second extinction session; E3 received $\mathrm{MgPe}$ at acquisition and the placebo at both extinction sessions; $C$ received the placebo at all sessions.

The criterion for acquisition was nine out of 10 successful avoidance responses; i.e., crossing from the shock side to the safe side before UCS onset. After this criterion was met, Ss were tested in extinction after $24 \mathrm{~h}$ and $72 \mathrm{~h}$. The criterion of extinction consisted of failure to make successive avoidance responses. The procedure in extinction was the same as in acquisition with the exception of UCS presentation. The intertrial interval, approximately 1 $\mathrm{min}$ for all trials, was the time lapse between replacement of $\mathrm{S}$ in the shock compartment and the beginning of the next trial.

Results. Since the latency scores were heterogeneous in variance a logarithmic transformation was performed in order to make the analysis of variance design applicable (posttransformation Cochran $C=0.33, p>.05$ ). The level of significance was set at 0.05 for all statistical tests. A significant difference was obtained between the drug groups and the control group for the first 10 acquisition trials with the drug groups having a shorter latency of response $(\mathrm{F}=6.30, \mathrm{df}=1 / 30, \mathrm{p}<.05)$ (see Fig. 1$)$.
The mean latency scores of each $\mathrm{S}$ on acquisition for the drug groups and the placebo group were analyzed with the MannWhitney U test. It was found that drug-treated Ss had a shorter mean avoidance time than did control Ss over all acquisition trials $(z=2.69, p=.01)$. The mean latency scores of the last nine avoidance trials were also compared for all groups. No significant differences were found, indicating that Ss learned the task to the same level in terms of latency of response as well as the number of trials to criterion. The acquisition data were also analyzed for proportion of avoidances, i.e., ratio of number of avoidance responses to the total number of acquisition responses. Drugtreated groups had a significantly higher ratio of avoidance responses than the placebo group $(\mathrm{z}=2.30, \mathrm{p}=.01)$.

The trials to criterion data in acquistion and extinction were analyzed using the Mann-Whitney $U$ test (see Table 1). In acquisition, Groups E1, E2, and E3 did not differ from $C$ as was predicted $(z=1.44, p=0.07)$. In the first extinction session $E l$, $E 2$, and $E 3$ did differ significantly from $C(z=1.86, p=.03)$. Also, the drug-treated groups (E1 and E2) differed significantly from placebo-treated groups (E3 and $C$ ) with the drug-treated groups requiring more trials to criterion $(z=1.85, p=0.03)$. In the second extinction session, Groups E1, E2, and E3 required significantly more trials to criterion than did $C(z=1.70, p=.04)$. However, the drug-treated group (E1) did not differ from the placebo-treated groups $(\mathrm{z}=1.22, \mathrm{p}=0.11)^{4.5}$

Discussion. From the results of the trials to criterion data in acquisition it must be concluded that there was no difference between the drug-treated and placebo-treated groups. However, other measures of acquisition did permit rejection of the hypothesis of no differences. The latency measures showed three important differences: (1) the drug-treated groups had significantly shorter latencies for the first 10 acquisition trials, which clearly supports the results of previous investigators (Plotnikoff, 1966; Beach \& Kimble, 1967; Frey \& Polidora, 1967); (2) the drug groups had a shorter mean avoidance time over all acquisition trials; and (3) the drug groups had a significantly higher proportion of avoidances. Beach \& Kimble (1967) have called the proportion of avoidances the most meaningful measure of learning. These data for acquisition indicate that $\mathrm{MgPe}$ did facilitate the learning of a conditioned avoidance response in terms of the latency of response and the proportion of avoidances, although the trials to criterion measure did not show this difference

In the first extinction session, the data indicated that there was a

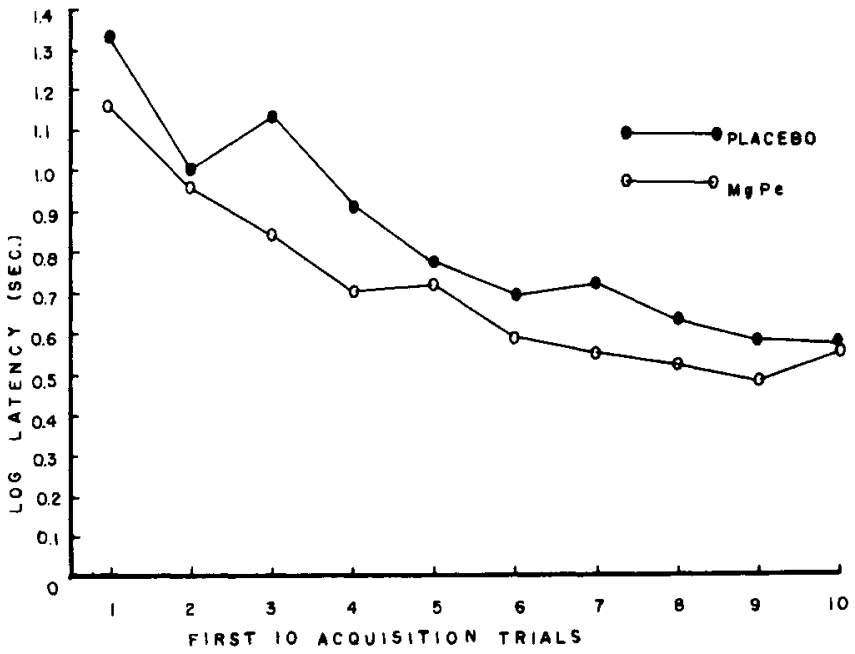

Fig. 1. Log latency of first 10 acquisition trials for combined drug groups and placebo group. 
Table 1

Means and Standard Deviations of Trials to Criterion Scores for all Groups and Sessions

\begin{tabular}{lccc} 
Group & Acquisition & Extinction 1 & Extinction 2 \\
El & MgPe & MgPe & MgPe \\
Mean & 17.75 & 19.38 & 8.13 \\
SD & 6.02 & 19.46 & 4.77 \\
\hline E2 & MgPe & MgPe & Placebo \\
Mean & 15.63 & 20.88 & 6.33 \\
SD & 4.25 & 18.60 & 2.27 \\
\hline E3 & MgPe & Placebo & Placebo \\
Mean & 14.38 & 11.63 & 5.75 \\
SD & 4.53 & 9.23 & 0.66 \\
\hline C & Placebo & Placebo & Placebo \\
Mean & 18.75 & 8.00 & 5.25 \\
SD & 4.29 & 4.56 & 4.77 \\
\hline
\end{tabular}

significant difference between combined drug groups and the placebo group, which may have been related to the effects of the acquisition process. Also in the first extinction session Groups E1 and E2 were significantly different from E3 and $C$. Thus the obtained differences between drug groups and placebo groups could be interpreted as due to either the effects of the drug or to the acquisition session.

In the second extinction session the only drug-treated group was not different from the placebo-treated groups. However, as in the first extinction session Groups E1, E2, and E3 combined were significantly different from $\mathrm{C}$. Again, the retention observed appears related to the acquisition session rather than to the effects of the drug.
In summary, it was concluded that the hypothesis of no difference in learning between groups could be rejected for the acquisition session. However, in evaluating the effects of $\mathrm{MgPe}$ on retention for both extinction sessions, it was concluded that there was no apparent relationship between drug-treated and placebo-treated groups. The only consistently significant differences in extinction were between the three groups that were treated with $\mathrm{MgPe}$ before acquisition and the placebo-treated group. Thus the observed differences in extinction appear related to the acquisition process and not to the effects of $\mathrm{MgPe}$.

\section{REFERENCES}

BEACH, F. R., \& KIMBLE, D. P. Activity and responsivity in rats after magnesium pemoline injections. Science, 1967, 155, 698-701.

FREY, P. W., \& POLIDORA, V. J. Magnesium pemoline: effect on avoidance conditioning in rats. Science, 1967, 155, 1281-1282.

MCCARROLL, J. E. \& KORBEL, SUSAN F. Avoidance learning and retention as a function of type of apparatus and CS interval. Psychol. Rep. 1967, 21, 261-264.

PLOTNIKOFF, N. Magnesium pemoline: enhancement of learning and memory of a conditioned avoidance response. Science, 1966, 15I, 703-704

\section{NOTES}

1. Submitted in partial fulfillment of the requirements for the M. A. Degree, University of Arkansas, where the first author is stationed under the auspices of the United States Army Graduate Psychology Student Program.

2. Thanks to Abbott Laboratories of North Chicago, especially to Dr. Hollis G. Schoepke who provided the MgPe and Dr. N. Plotnikoff who provided the carboxymethylcellulose and answered questions concerning the use of the drug.

3. Thanks to Richard L. Rogers, Kenneth D. Johnson, and Adine Johnson who injected all animals, kept track of experimental records and administered the blind technique of experimentation.

4. Thanks to Drs. W. J. Richards and R. H. Hickson for their assistance on this project.

5. Data for this experiment are on file in the Office of the editor. A copy may be obtained free of charge upon request. 